\section{A cognitive-behavior therapy applied to a social anxiety disorder and a specific phobia, case study}

\author{
George D. Tsitsas, Antonia A. Paschali \\ Counseling Center, Harokopio University; \\ Faculty of Nursing, National and \\ Kapodistrian University of Athens, \\ Greece
}

\section{Abstract}

George, a 23-year-old Greek student, was referred by a psychiatrist for treatment to a University Counseling Centre in Athens. He was diagnosed with social anxiety disorder and specific phobia situational type. He was complaining of panic attacks and severe symptoms of anxiety. These symptoms were triggered when in certain social situations and also when travelling by plane, driving a car and visiting tall buildings or high places. His symptoms lead him to avoid finding himself in such situations, to the point that it had affected his daily life. George was diagnosed with social anxiety disorder and with specific phobia, situational type (in this case acrophobia) and was given 20 individual sessions of cognitivebehavior therapy. Following therapy, and follow-up occurring one month post treatment, George no longer met the criteria for social phobia and symptoms leading to acrophobia were reduced. He demonstrated improvements in many areas including driving a car in and out of Athens and visiting tall buildings.

\section{Introduction}

Social anxiety disorder (SAD), also known as social phobia, is one of the most common anxiety disorders. Social phobia can be described as an anxiety disorder characterized by strong, persisting fear and avoidance of social situations. 1,2 According to DSMIV, 3 the person experiences a significant fear of showing embarrassing reactions in a social situation, of being evaluated negatively by people they are not familiar with and a desire to avoid finding themselves in the situations they fear. ${ }^{4,5}$ Furthermore people with generalized social phobia have great distress in a wide range of social situations. ${ }^{6}$ T he lack of clear definition of social phobia has been reported by clinicians and researchers because features of social phobia overlap with those of other anxiety disorders such as specific panic disorder, agoraphobia and shyness. ${ }^{7}$
According to ICD-10, ${ }^{8}$ phobic anxiety disorders is a group of disorders in which anxiety is evoked only, or predominantly, in certain welldefined situations that are not currently dangerous. As a result these situations are characteristically avoided or endured with dread. The patient's concern may be focused on individual symptoms like palpitations or feeling faint and is often associated with secondary fears of dying, losing control, or going mad. Contemplating entry to the phobic situation usually generates anticipatory anxiety. Phobic anxiety and depression often coexist. Whether two diagnoses, phobic anxiety and depressive episode, are needed, or only one, is determined by the time course of the two conditions and by therapeutic considerations at the time of consultation.

Prevalence of social phobia varies from 0 $20 \%$, depending on differences in the classification criteria, culture ${ }^{9,10}$ and gender. ${ }^{11-13}$ The onset of the disorder is considered to take place between the middle and late teens. ${ }^{14}$ The NICE guidelines for social anxiety disorder, describe it as one of the most common of the anxiety disorders. Estimates of lifetime prevalence vary but according to a US study, $12 \%$ of adults in the US will have social anxiety disorder at some point in their lives, compared with estimates of around $6 \%$ for generalized anxiety disorder (GAD), 5\% for panic disorder, $7 \%$ for post-traumatic stress disorder (PTSD) and $2 \%$ for obsessive-compulsive disorder. There is a significant degree of comorbidity between social anxiety disorder and other mental health problems, most notably depression (19\%), substance-use disorder (17\%), GAD (5\%), panic disorder (6\%), and PTSD (3\%). ${ }^{15}$

Social phobia is also developed and maintained by complex physiological, cognitive, and behavioral mechanisms. Biological causes of social anxiety/phobia have been reported by some researchers while others look on behavioral inhibition ${ }^{16}$ and the effects of personality traits such as neuroticism and introversion ${ }^{17}$ as the mediators between genetic factors and social phobia.

Apart from the biological factor, the role of cognition in the acquisition and maintenance of social anxiety/phobia is very important. The main cognitive factor is the fear of negative evaluation. 18 Beck, Emery, and Greenberg 19 associated the possibility of negative evaluation by others with beliefs of general social inadequacy, concerns about the visibility of anxiety, and preoccupation with performance or arousal..$^{20}$

Specific phobia situational type, is described as a persistent fear that is excessive or unreasonable cued by the presence or anticipation of a specific object or situation such as public transportation, tunnels, bridges, elevators, flying, driving or enclosed places. This subtype has a bimodal age-at-onset distribu-
Correspondence: Antonia A. Paschali, Department of Mental Health and Behavioral Sciences, National and Kapodistrian University of Athens, 123 Papadiamantopoulou street, 11527 Athens, Greece.

E-mail: anpascha@nurs.uoa.gr

Key words: social phobia, specific phobia situational type, high places, cognitive behavior therapy.

Contributions: AP and GT designed the protocol, administer the CBT therapy sessions, analyzed and interpreted the data, and wrote the paper.

Conflict of interests: the authors declare no potential conflict of interests.

Received for publication: 22 April 2014.

Revision received: 1 July 2014.

Accepted for publication: 4 July 2014.

This work is licensed under a Creative Commons Attribution NonCommercial 3.0 License (CC BYNC 3.0).

(C) Copyright G.D. Tsitsas and A.A. Paschali et al., 2014

Licensee PAGEPress, Italy

Health Psychology Research 2014; 2:1603

doi:10.4081/hpr.2014.1603

tion with one peak in childhood and another peak in mid-20s. ${ }^{21}$

Exposure to the phobic stimulus almost invariably provokes an immediate anxiety response which may take the form of a situational bound or situational predisposed panic attack. The phobic situation usually is avoided or else is endured with intense anxiety or distress. The avoidance interferes often with the person's normal routine occupational functioning, social activities or relationships. ${ }^{21}$ Fear of heights, or acrophobia, is one of the most frequent subtypes of specific phobia frequently associated to depression and other anxiety disorders. ${ }^{22}$ It is one of the most prevalent phobias, affecting perhaps 1 in 20 adults. Heights often evoke fear in the general population too, and this suggests that acrophobia might actually represent the hypersensitive manifestation of an everyday, rational fear. 23

From a behavioral perspective, feared situations negatively maintain phobias. Anxiety disorders have been shown to be effectively treated using cognitive behavior therapy (CBT) and therefore to better understand and effectively treat phobias. The CBT model used in the present case, was based on Clark and Wells ${ }^{24}$ model that places emphasis on self-focused attention as social anxiety is associated with reduced processing of external social cues. The model pays particular attention to the factors that prevent people, who suffer from social phobias, 
from changing their negative beliefs about the danger inherent in certain social situations.

The following case it is a good representation of this model.

\section{Case Report}

George, was a 23-year-old single, Caucasian male student in his last academic year and was referred to a University Counseling Centre in Athens. The Centre provides free of charge, treatment sessions to all University students requiring psychological support.

George was diagnosed with Social Anxiety Disorder and with Specific phobia, Situational Type i.e. acrophobia. He was living alone in Athens, as his parents live in a different region of Greece. He was an only child. When asked about his childhood, he said that he had been happy and did not report any traumatic events. He described a close relationship with both his parents and when asked, he did not report any family history of psychiatric or psychological disorders or substance abuse problems.

He complained of severe symptoms of anxiety and phobias during the last six months. He began experiencing severe heart palpitations, flushing, fear of fainting and losing control, when travelling by plane, when crossing tall bridges while driving or when being in tall buildings or high places, however he did not experience symptoms of vertigo. Additionally, he reported significant chest pain and muscle tension in feared situations. His fear of experiencing these symptoms worsened and led him to avoid these situations which made his everyday life difficult. He also experienced similar symptoms when introduced to people or meeting people for the first time. He repeatedly went to see various doctors many times in order to exclude any medical conditions. George stated that he didn't experience any symptoms of depression, had no prior psychological or psychiatric treatment and/or medication, and had first experienced this problem in the course of the previous year.

At the time of the intake, George was in his final exams which he wanted to finish successfully, and continue his studies abroad. Due to his condition, he decided not to apply for a postgraduate degree in the United Kingdom, which he always wanted, and started looking for alternative postgraduate courses in Greece.

\section{Assessment and treatment}

George was referred by a private psychiatrist. The psychiatrist used the Mini International Neuropsychiatric Interview, ${ }^{25}$ which is a structured interview based on DSMIV diagnostic criteria. George met the criteria for a Social anxiety disorder. He also met the criteria for specific phobia limited-symptom, which was secondary to his social phobia. The psychiatrist suggested to George, to better help him with his current symptoms to take selective serotonin reuptake inhibitors (SSRIs). George however refused to take any medication and the psychiatrist referred him to the Counseling Centre. For the specific case we decided to give individual cognitive behavior therapy based on Clark and Wells model for Social Anxiety Disorder, ${ }^{24}$ as referred into the NICE guidelines. ${ }^{26}$ To better assist conceptualization and treatment and also monitor his progress, two therapists were assigned to George and two assessment measures (STAI and SPAI) were given, prior to the course of treatment, following therapy and at one month follow-up. He also had to complete a self-monitoring scale through-out the 20 weeks of treatment.

\section{Monitoring progress measures}

\section{State-Trait Anxiety Inventory}

The state-trait anxiety inventory (STAI),, 27 the appropriate instrument for measuring anxiety in adults, differentiates between state anxiety, which represents the temporary condition and trait anxiety, which is the general condition. The STAI includes forty questions, with a range of four possible responses. In each of the two subscales scores range from 20 to 80 , high scores indicating a high anxiety level. Higher scores correspond to greater anxiety.

\section{Social Phobia and Anxiety Inventory}

The Social Phobia and Anxiety Inventory (SPAI) $^{28}$ is a 45 item self-report measure that assesses cognition, physical symptoms, and avoidance/escape behavior in various situations. It includes two subscales: Social Phobia and Agoraphobia. A difference score above 60 indicates a potential phobia, and a cut off score of 80 maximizes this identification rate.

George's pre-treatment scores were, SPAI:126, State Anxiety: 64 and Trait Anxiety: 63. The ultimate goal in each situation was to reduce the client's level of anxiety.

Cognitive-behavior techniques such as selfmonitoring, cognitive restructuring, relaxation, breathing retraining, and assertiveness training were employed to reduce anxiety and fear.

\section{Cognitive behavior therapy techniques}

\section{Self-monitoring}

Self-monitoring refers to the systematic observation and recording of one's own behaviors or experiences on several occasions over a period of time. ${ }^{29}$ Self-monitoring can be used as a therapeutic intervention, because it helps the patient to evaluate his/her thoughts, emotions, and behaviors, recognize the feared situations and find appropriate solutions. Kazdin ${ }^{30}$ states that self-monitoring can lead to dramatic changes, while Korotitsch and Nelson-Gray ${ }^{29}$ add that although the therapeutic effects of self-monitoring may be small, they are rather immediate. George was asked to monitor his thoughts, feelings, and behaviors and record any changes.

George had to complete an Every Day SelfMonitoring Scale for 20 weeks measuring feelings of anxiety $(0=$ no anxiety to $10=$ most anxiety) and phobia $(0=$ no feelings of phobia to $10=$ most feelings of phobia), (Figure 1).

\section{Cognitive restructuring}

Beck and Emery, ${ }^{19}$ have identified three phases in cognitive restructuring: i) identification of dysfunctional thoughts ii) modification of dysfunctional thoughts and iii) assimi-

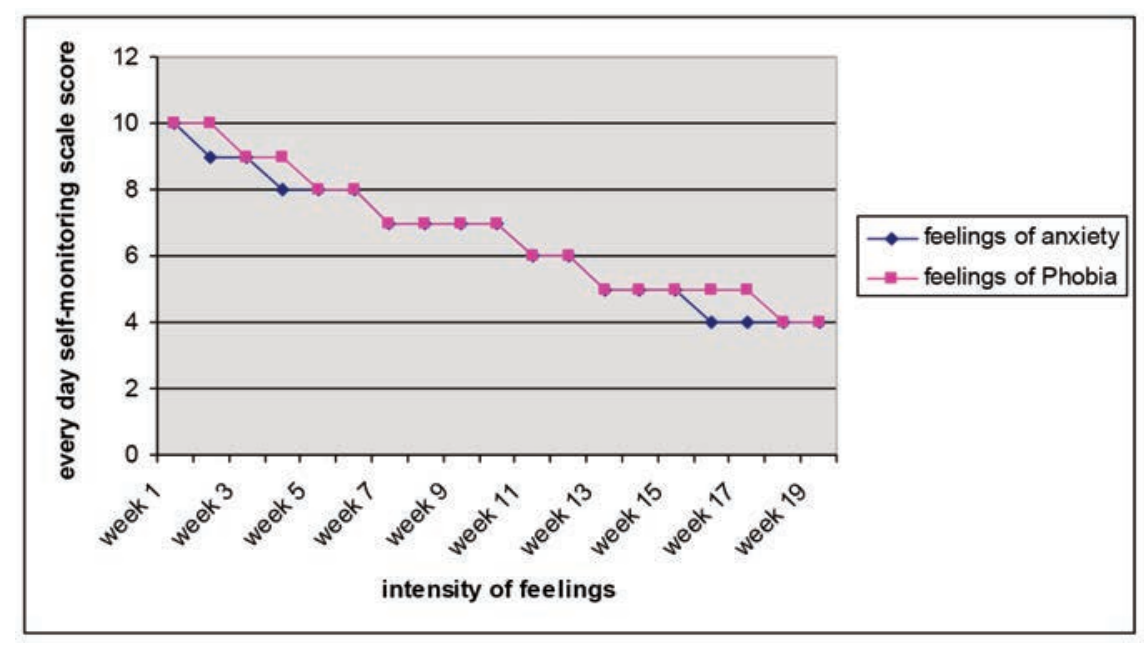

Figure 1. Every day self-monitoring scale score. 
lation of functional thoughts. During cognitive restructuring, the client starts recognizing his/her automatic or dysfunctional thoughts and emotions that derive from this thoughts. For example, one of George's thoughts was that: it is dangerous to drive at night, which made him feel very anxious and frightened. However, an adaptive thought could be that: that sometimes is dangerous but also a lot of times are not, due the fact that at night there is less traffic in the streets. Therefore, throughout the sessions he was taught how to substitute several automatic negative thoughts with adaptive ones. He also kept a dysfunctional thought record for 6 sessions, which he discussed with his therapist every week.

\section{Muscle relaxation}

Relaxation techniques were used for the treatment of George's symptoms and more specifically for the physiological manifestations of anxiety and panic. ${ }^{31}$

George was trained in breathing and muscle relaxation exercises, based on Jacobson's technique and he was given 8 relaxation training sessions, in order to establish a sense of control over his physical symptoms. The client learned to apply brief muscle relaxation exercises in his daily life and especially every time he had to face an uncomfortable situation.

\section{Assertiveness training}

Assertiveness training can be an effective part of treatment for many conditions, such as depression, social anxiety, and problems resulting from unexpressed anger. Assertiveness training can also be useful for those who wish to improve their interpersonal skills and sense of self-respect and it is based on the idea that assertiveness is not inborn, but is a learned behavior. Although some people may seem to be more naturally assertive than others are, anyone can learn to be more assertive. In the specific case the therapists helped George figure out which interpersonal situations are problematic to him and which behaviors need the most attention. In addition, helped to identify beliefs and attitudes the client might had developed, that lead him to become too passive. The therapist used roleplaying exercises as part of this assessment.

\section{Clinical sessions}

George completed 20 individual, $50 \mathrm{~min}$ therapy sessions that took place within a period of 5 months. During the first session the rationale of the cognitive-behavioral treatment was analyzed and special emphasis was given to educate the patient on Social Anxiety disorder and Specific phobias. An introduction was made to the role that automatic thoughts play in our cognitions and helped him to recognize automatic negative thoughts and feelings. A self-monitoring diary of anxiety was given to him as homework. Emphasis was also given to establishing good rapport and collaboration in the therapeutic relationship. During the second session, George narrated stressful life events and reported specific cases in which the anxiety symptoms increased. He was also taught how to identify the three phases of cognitive restructuring and was given the dysfunctional thought record as homework. The third session was based on teaching him breathing exercises and muscle relaxation. Relaxation techniques were taught by a different therapist, with expertise in stress management and relaxation techniques. George was given 8 such sessions, each lasting 20 minutes while he also practiced the sessions daily at home and completed a Daily-form for progress monitoring.

Sessions 4 to 9 were devoted to ways of challenging dysfunctional thoughts by resorting to adaptive responses. At first we tried to recognize negative automatic thoughts during specific situations and record George's mood in that situation. After recognizing George's negative thoughts, emotions and behaviors, we worked on the evidence that supported these thoughts.

The next three sessions (10-12) were devot- ed to teach him assertiveness skills to learn to socialize with people more effectively. We explored what assertiveness meant for George, what prevented him from being assertive and what were the differences between assertive, submissive and aggressive behavior, which he found really helpful and role-playing exercises were initiated to exercise these skills.

Sessions 13-20 were devoted identifying anxiety provoking situations which were hierarchically classified according to the degree of anxiety they produced. An example is shown in Table 1. Exposure to feared situations was performed by facing in vivo each level of the hierarchy and gradually practice each step, until he was confident enough to go on to the next.

Accordingly, situations such as driving, crossing bridges etc were also explored.

During the last session, George referred to overcoming challenging experiences, such as meeting new people, visiting friends living in tall apartment buildings and crossing two high bridges, while driving to visit his parents in a different part of Greece. He effectively challenged his cognitions in all relevant situations and utilized muscle relaxation and breathing exercises to control feelings of anxiety. Last session was also devoted to discuss relapse

Table 1. Fear hierarchy for visiting tall buildings.

\begin{tabular}{ll} 
Level & Fear \\
1 & Visit a tall building \\
\hline 3 & Visit the second floor of a tall building with a family member \\
\hline 4 & Visit the second floor of a tall building alone \\
\hline 5 & Visit the third floor of a tall building with a family member \\
\hline 6 & Visit the third floor of a tall building alone \\
\hline 7 & Stay at the third floor of a tall building with a family member for $15 \mathrm{~min}$ \\
\hline
\end{tabular}

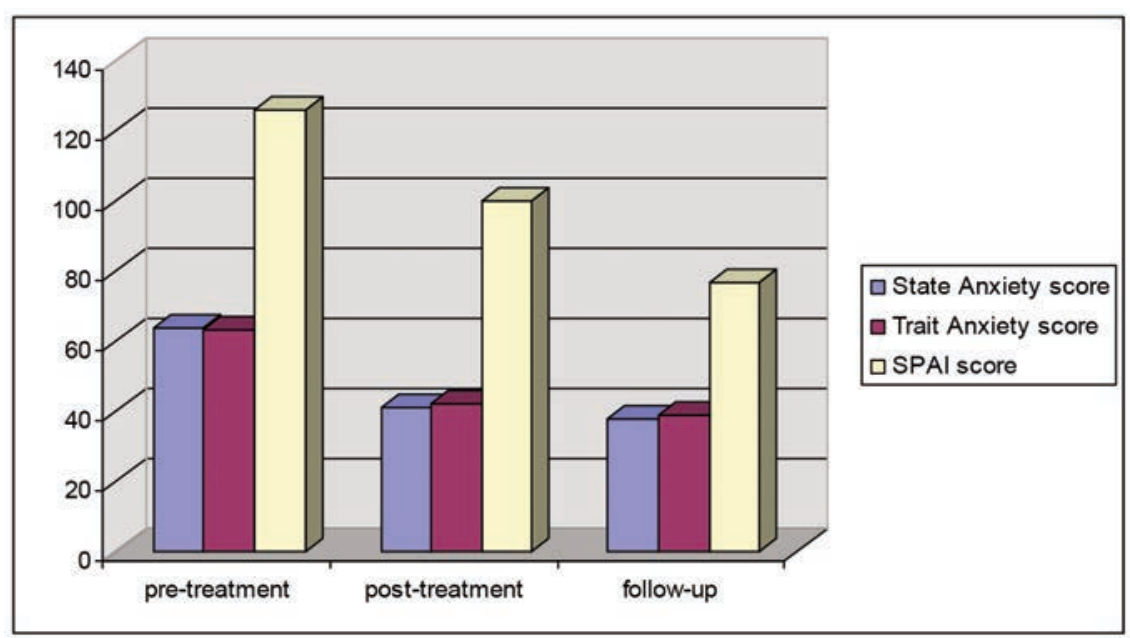

Figure 2. STAI and SPAI Scores. 
prevention, ways to avoid it and how to overcome past failures and difficulties. Finally, we discussed how he could modify and apply the skills and techniques that he had learned, in his daily routine.

The post-treatment scores of STAI and SPAI obtained by George at termination indicated an improvement. The Social Phobia score dropped to 100, the Anxiety State score was 41 and the Trait score was 42 .

During the follow-up session one month later, George talked about his improvement, he mentioned that his progress continued and that he was not experiencing any of the averse symptoms of the past, while driving, visiting tall buildings/bridges and meeting new people. He continued the relaxation and the cognitive restructuring exercises. The STAI \& SPAI scales were administered again. The assessment revealed maintenance of gains in terms of reduced anxiety and fear symptoms with State anxiety score: 38 , Trait anxiety score: 39 and SPAI score: 77 (Figure 2).

\section{Discussion}

\section{Treatment implications}

In the present clinical case, George attended 20 individual sessions of CBT, in order to reduce his anxiety levels and phobias and learn how to monitor his progress in his daily life. His anxiety levels were reduced in social situations and also he managed to overcome his fear of heights in specific provoking situations. His progress was inevitable which was confirmed by the anxiety scores of the STAI and SPAI. The follow-up session that took place a month later, showed that his progress was sustained. The Every Day Self-Monitoring Scale during the 20 weeks period, showed a gradual reduction in self monitoring feelings of anxiety and phobias (Figure 1).

However although we based our CBT model on Clark and Wells model for Social Anxiety, we had certain variations from the original model. For example, the Clark and Wells model suggests, that individual therapy for social anxiety disorder should consist of up to 14 sessions of 90 minutes' duration over approximately 4 months. In our case study, the duration of each session lasted 50 minutes and we gave 20 sessions of individual therapy to our client over a period of 5 months, thus trying to tailor our client's needs and requirements for treatment.

A good rapport was developed with George and that helped the entire treatment process. Working on a list of feared hierarchies in combination with relaxation training skills, George was able to manifest his high level anxiety visiting tall buildings, crossing tall bridges etc. Furthermore, the fact that George learned to identify his automatic thoughts, helped him to reduce his unpleasant feelings by alternating his thoughts. Role-playing exercises in order to acquire assertiveness training skills helped him in relation to meeting new people. It is also worth mentioning that George was motivated and completed his CBT homework every week, something that helped the therapeutic outcome.

\section{Conclusions: recommendations to clinicians and students}

Cognitive behavioral therapy is very effective in treating anxiety. It is a structured intervention that follows a general framework that is modified for each individual. For the successful treatment of social phobia, the cognitive behavior therapy must be thorough and comprehensive. Sometimes is needed to use combinations of techniques, like in this case we used traditional CBT techniques in combination with assertiveness skills training. Collaboration with other specialists is also advised for ultimate results, as in this case two therapists were involved, one main therapist and one specialist on stress management techniques. The cognitive-behavior therapist is important to adapt the session, on the basis of his/her client's needs, for example in the case of George we used exposure based techniques and although the Counseling center offers a maximum of 6 therapeutic sessions, in the case of George we decided on 20 sessions, in order to fully accommodate his problem. It is also very important for the therapist to explain the rationale behind each CBT session and help the patient understand each session's agenda up to the point he/she feels comfortable to set their own agenda during the session. However, despite the therapist's best efforts, the patient often hesitates to carry out the everyday homework, thus sometimes delaying the therapeutic progress. Therefore, the good rapport established with the patient will almost certainly add greatly to his/her adherence during the treatment.

Therapist-client relationship, play a fundamental role in the therapy process. It is important for the client to trust the therapist and feel comfortable within the therapy context. Creating a safe and empathetic environment is important from the first therapy session. Furthermore as CBT is directive, a strong therapeutic alliance is necessary to allow the client to feel safe engaging in this type of therapy. It is also important to mention that therapists need to refer to the widely accepted guidelines and recommendations for treating Social anxiety disorders and specific phobias, from widely accepted national institutes, such as the National Institute for Health and Care Excellence that covers both pharmaceutical and psychotherapeutic approaches. However, it is necessary sometimes to tailor-made therapy around client's needs, as each case must be seen individually. There are too many manuals on CBT and there is the danger for the therapist to work in such a program that can lose creativity, individual thought, imagination and contact with the client. The crucial role of any therapeutic intervention, is not only to help people to acquire the techniques, but to feel comfortable to apply them daily in situations they feel discomfort.

\section{References}

1. Kaplan H, Sadock B. Synopsis of psychiatry. 8th ed. Baltimore: Williams \& Wilkins; 1998.

2. Hazen AL, Walker JR, Stein MB. Comparison of anxiety sensitivity in panic disorder and social phobia. Anxiety 1995;1:298-301.

3. American Psychiatric Association. Diagnostic and statistical manual of mental disorders: DSM-IV-TR. Washington, DC: American Psychiatric Association, 2000.

4. Bruch MA, Cheek JM. Developmental factors in childhood and adolescent shyness. In: Heimberg RG, Liebowitz MR, Hope DA, Schneier FR, eds. Social phobia: diagnosis, assessment and treatment New York: Guilford Press; 1995. pp 163-184.

5. Rapee RM. Descriptive psychopathology of social phobia. In: Heimberg RG, Liebowitz MR, Hope DA, Schneier FR, eds. Social phobia: diagnosis, assessment and treatment New York: Guilford Press; 1995. pp 41-68.

6. Adelman L. Don't call me shy. Austin, TX: Langmarc Publishing; 2007.

7. Beidel DC, Morris TL, Turner MW. Social phobia. In: Morris TL, March JS, eds. Anxiety disorders in children and adolescents. 2nd ed. New York: Guilford; 2004. pp 141-163.

8. World Health Organization. ICD-10 Version:2010. Phobic anxiety disorders. Available from: http://apps.who.int/classifications/icd10/browse/2010/en\#/F40.

9. Browne MAO, Wells JE, Scott KM, McGee MA. Lifetime prevalence and projected lifetime risk of DSM-IV disorders in Te Rau Hinengaro: the New Zealand mental health survey. Aust N Z J Psychiatry 2006;40:865-74.

10. Wittchen HU, Fehm L. Epidemiology and natural course of social fears and social phobia. Acta Psychiatr Scand Supp 2003;417:4-18.

11. Kessler RC, McGonagle K, Zhao S, et al. Lifetime and 12-month prevalence of DSM-III-R psychiatric disorders in the 
United States: results from the National comorbidity survey. Arch Gen Psychiatry 1994;51:8-19.

12. Antony MM, Barlow DH. Social and specific phobias. In: Tasman A, Kay J, Lieberman JA, eds. Psychiatry. Philadelphia: WB Saunders; 1997.

13. Schneier FR, Johnson J, Hornig CD, et al. Social phobia: comorbidity and morbidity in an epidemiological sample. Arch Gen Psychiatry 1992;49:282-8.

14. Wells JE, Browne MAO, Scott KM, et al. Prevalence, interference with life and severity of 12 month DSM-IV disorders in Te Rau Hinengaro: the New Zealand mental health survey. Aust N Z J Psychiatry 2006;40:845-54.

15. National Institute for Health and Care Excellence. Social anxiety disorder: recognition, assessment and treatment. [NICE Clinical Guideline 159]. Available from: https://www.nice.org.uk/guidance/cg159

16. Schmidt LA, Polak CP, Spooner AL. Biological and environmental contributions to childhood shyness: a diathesisstress model. In: Crozier WR, Alden LE, eds. The essential handbook of social anxiety for clinicians. Hoboken: John Wiley \& Sons; 2001. pp 33-55.

17. Stemberger RT, Turner SM, Beidel DC, Calhoun KS. Social phobia: an analysis of possible development factors. J Abnormal
Psychol 1995;104:525-31.

18. Mattick RP, Page A, Lampe L. Cognitive and behavioural aspects. In: Stein M, ed. Social phobia: cinical and research perspectives. Washington: American Psychiatric Press; 1995.

19. Beck AT, Emery G, Greenberg R. Anxiety disorders and phobias: a cognitive perspective. New York: Basic Books; 1985.

20. Hartman LM. A metacognitive model of social anxiety: implications for treatment. Clin Psychol Rev 1983;3:435-56.

21. American Psychiatric Association, DSM-IV, 4th ed. Text revision. Washington, DC, American Psychiatric Association; 2000.

22. Coelho CM, Wallis G. Deconstructing acrophobia: physiological and psychological precursors to developing a fear of heights. Depress Anxiety 2010;27:864-70.

23. Boffino CC, de Sá CS, Gorenstein C, et al. Fear of heights: cognitive performance and postural control. Eur Arch Psychiatry Clin Neurosci 2009;259:114-9.

24. Clark DM, Wells A. A cognitive model of social phobia. In: Heimberg R, Liebowitz M, Hope DA, Schneier FR, eds. Social phobia: Diagnosis, assessment and treatment. New York: Guilford Press; 1995. pp 69-93.

25. Sheehan DV, Lecrubier Y, Janavs J, et al. Mini international neuropsychiatric interview (M.I.N.I.). Tampa: University of South Florida Institute for Research in
Psychiatry; 1994.

26. National Institute for Health and Care Excellence. Generalised anxiety disorder and panic disorder (with or without agoraphobia) in adults: management in primary, secondary and community care. [NICE Clinical Guideline 113]. Available from: http://www.nice.org.uk/ guidance/cg113/chapter/guidance

27. Spielberger CD, Gorsuch RL, Lushene RE. Manual for the state-trait anxiety inventory. Palo Alto, CA: Consulting Psychologists Press; 1970.

28. Turner SM, Beidel DC, Dancu CV, Stanley MA. An empirically derived inventory to measure social fears and anxiety. Psychologic Assess 1989;1:35-40.

29. Korotitsch WJ, Nelson-Gray RO. Self-monitoring in behavioral assessment. In: Fernandez-Ballesteros R, ed. Encyclopedia of behavioral assessment. London: Sage; 2003. pp 853-858.

30. Kazdin AE. Behavior modification in applied settings. Belmont, CA: Wadsworth; 2001.

31. Barlow DH, Craske MG. Mastery of your anxiety and workbook. 2nd ed. San Antonio, TX: The Psychology Corporation: 1994. 